\title{
The causal mechanism of migration behaviors of African immigrants in Guangzhou: from the perspective of cumulative causation theory
}

Yucheng Liang

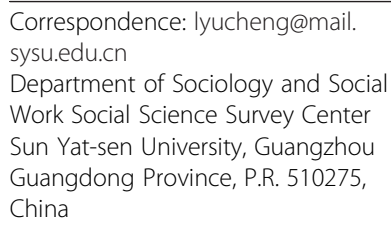

Correspondence: lyucheng@mail. sysu.edu.cn

Department of Sociology and Social Work Social Science Survey Center Sun Yat-sen University, Guangzhou Guangdong Province, P.R. 510275, China

\begin{abstract}
This study tests international migration theory, especially cumulative causation theory, by looking into the causal mechanisms of international migration behavior among African immigrants in China by using the respondent-driven sampling method since African immigrants in China belong to a small hidden population. This method collected a representative sample $(N=648)$ from two locations in 2011. The paper reveals that the immigration behaviors of African immigrants in China from 2005 to 2011 have characteristics similar to international immigrants in initial stages - the cumulative causal effects of immigrants' social capital was continually strengthened during the reproduction of migration behavior in the sending countries. Consequently, given the sustainable economic growth and maintenance of a stable society in China, the scale of future transnational immigration (including illegal migration) will continue to expand. The paper proposes that at the present stage, existing policies should raise the entry threshold of African immigrants into China in order to mitigate the speed and scale of migrants' social class decline.
\end{abstract}

Keywords: African immigrants; Immigrants; Illegal residence; Cumulative causation theory; Respondent-driven sampling

\section{Background}

Under the background of the opening-up policy, China's export-oriented economy has developed further. China has become the world's second largest economy and exporter over more than 30 years of rapid economic growth. Increased communication and cooperation between China and other countries has led to a rise in the number of foreigners who come to China.

The result of the Sixth Population Census shows that (National Bureau of Statistics 2011) $62 \%$ of all international immigrants in China are located in Beijing, Shanghai, and Guangdong. Among them, Guangdong takes the highest proportion - more than one third. Guangzhou, the capital city of Guangdong province, differs from Beijing and Shanghai in that among the international immigrants who live in Guangzhou and nearby cities, African immigrants make up the highest proportion. The influx and settling of large numbers of African immigrants in Guangzhou have caused problems of illegal residence, illegal immigration, and illegal employment (also known as 'the three illegals').

A common pattern can be found throughout the evolution of immigration history in many developed countries: The issue of immigration is a peripheral social issue at first,

(c) 2014 Liang; licensee Springer. This is an Open Access article distributed under the terms of the Creative Commons Attribution License (http://creativecommons.org/licenses/by/4.0), which permits unrestricted use, distribution, and reproduction in any medium, provided the original work is properly credited. 
but it gradually evolves into a critical social issue that impacts the entire country's politics, economy, society, culture, religion, and national security (Stalker 2001). Almost all developed countries today are facing social problems caused by immigration and illegal immigrants. Thus, the sooner China can sort out its immigration laws, the better.

\section{Reflections on theories of international migration in the developing world Macroscopic theories of international migration}

Macrotheories include the push-pull theory, the labor market segregation theory, and the world-system theory. The push-pull theory considers migration flows as the result of the joint effects of both push and pull factors, and conforms to certain patterns. In the push-pull model, push factors refer to all forces in migrants' countries of origin that are not conducive to one's survival and development, such as wars, riots, natural disasters, environmental degradation, and other factors that cause misfortune to small groups and force people to leave their homes. Pull factors refer to the attractiveness of migrant destinations; these do not necessarily mean better living conditions although attractive destinations tend to offer more opportunities for earning a living and individual development. In short, the push-pull theory deals with how the negative factors of place of origin and positive factors of the destination influence people's migration behaviors (Petersen 1958).

The labor market segmentation theory is also known as 'the dual labor market theory' (Massey 1995). Through analyzing the market structure of developed countries, this theory finds the presence of a dual labor market: a superior labor market with high efficiency, security, welfare, and comfortable working environment, and a lower labor market with low wages, instability, few promotion opportunities, and poor working conditions. It is easy to recruit staff in the former market since the local workforce aspires to hold these attractive positions. The lower market, on the other hand, is difficult to fill due to local negative attitude toward low-quality positions. This externalizes the labor markets of developed countries that have an internal demand for foreign labor, which promotes cross-national migration.

Immanuel Wallerstein's 'Modern World System' theory points out that the economic and political inequality of development between countries is the main driving force of international immigration. It argues that the essence of transnational migration is the expansion and penetration of production modes of capitalism. This spreads from core countries to peripheral countries, which are forced to engage in the global economy led by core states. This causes drastic changes in the social, economic, and political structures of peripheral states, making traditional ways of living difficult to maintain. With the collapse of traditional society, people gradually leave their original society and move to new places, resulting in the emergence of international migration (Wallerstein 2006).

\section{Microscopic theories of international migration}

Microscopic theories that focus on explaining immigrant behaviors mainly include neoclassical economic theory, human capital theory, the new economics of migration, social capital and social network theory, and cumulative causation theory. Neoclassical economic theory suggests that international migration is an individual's choice to maximize his/her own benefit as an investment in human capital; the fundamental reason for this is the income gap between countries. The flow of immigration continues until these wage gaps disappear, whereupon migration behaviors will subside (Stark and Bloom 1985). 
Human capital theory claims that the possibility of international migration is related to an individual's age, gender, education, skills, relevant work experience, and marital status. In order to obtain a higher return on human capital, individuals will take risks and change their language, culture, and social environment (Grubel and Scott 1966). The new economics of migration attributes migration decisions and behaviors not to absolute income gaps between countries, but rather to the relative deprivation that actors realizes when comparing themselves to reference groups (Stark and Taylor 1989, 1991). The new economics of migration breaks the traditional mode of migration theories that place individuals in a social vacuum. It challenges the assumptions regarding markets' function in departure countries that trigger migration and regards market failure as the causation of individuals' migration behavior, which is due to imperfect and monopolistic market competition in the departure country. Network theory proposes that various special relationships based on kinship and friendship between migrants and their relatives and friends in the original country are a combination of a series of relationships, which can be kinship ties, township ties, romantic relationships, etc. (Greenwood 1971; Nelson 1976; Massey et al. 1987). It emphasizes the role of network relations in immigrants' departure and arrival communities. Immigrants' social networks have four roles: providing information that reduces migration cost, reducing the difficulty of acculturation, helping new immigrants find jobs and improving their expectations of revenue, and helping new immigrants save various types of expenses.

Massey et al. proposes a cumulative causation theory based on the social capital theory of immigrants (Massey et al. 1987; Massey 1988, 1990a, 1995). They believe that after the formation of immigrant networks, information regarding immigration may be more accurate and more widespread, which reduces the cost of immigration and, consequently, continuously promotes future migration; additionally, as time goes by, immigrants directed to specific foreign regions can integrate themselves into a more familiar environment. Their migrations are no longer related with the earlier specific economic and political conditions of the destination country. Instead, migration behaviors are more likely to be determined by the degree of association of migration networks, accumulated social capital of migration networks, and so forth. Consequently, migration processes have an internal mechanism of self-development and self-perpetuation. Although this theory cannot explain the initial occurrence of migration behavior, it can explain their continuality and helps predict trends of future migration. The theory of cumulative causation argues that factors other than migration networks slowly become less important, while the migration networks in places of origin can be self-evolving and cumulative; migration behaviors will have their own internal self-continuity. When migration behaviors are internalized as derivative habits that transcend the control of consciousness, they are acknowledged within the migration group and thus continue, even if the environments that led to the original migration behaviors have changed or even if the migration behaviors are considered irrational by outsiders. Each migration influences the social and economic structures of both the departure and destination countries, thus perpetuating subsequent migrations.

There are two types of migration networks: one is a network connecting the country of origin and the destination and the second is the immigrant's social network at their destination. As time goes by, network connections play an increasingly important role 
in influencing people's migration behavior in the origin country. Thus, more and more people will migrate to target countries, which in turn enhances the connections between departure and destination. The longer an immigrant lives in a destination country, the better the quality of information and resources he or she can provide to potential immigrants. Based on the cumulative causation theory, (Massey 1990b) proposes the phenomenon of class decline in the early stages of migrations. He examined the migration process of Mexican immigrants to the USA and found that in the early stages of migration, migrants often came from the middle class and were more likely to be able to afford expensive migration costs compared to the lower classes. Compared to the higher classes, the middle class also had stronger motivation to migrate in order to increase their developmental opportunities. However, as social networks matured during the migration process, migration costs gradually declined, and a downward shift in the social class of migrants gradually appeared due to the cumulative effects of migration.

Criticism of the cumulative causation theory must be mentioned. First, the model is more applicable to discussing the condition of emigration when the original society is an agricultural community and lacking urban economic characteristics (Liang et al. 2008). This is because rural areas are more likely to be a homogeneous society that easily sustains social networks, whereas cities are more like a heterogeneous society in which maintaining social networks is more difficult (Liang et al. 2008). Second, the cumulative causation model measures the social networks of migrants as their network relations connecting communities of departure and communities of arrival, which requires researchers to measure the number of connections that a migrant has at his or her destination before he or she arrives. Thus, the cumulative causation model has relatively high requirements for data collection. In practice, studies aiming at verifying this theory generally need longitudinal data, which adds difficulty to such studies.

The cumulative causation model merits another criticism: This model is mainly applicable in discussing migrants with connections between the departure and the destination societies. For migrants without these connections, the theoretical basis of this model no longer exists. Thus, for migration caused by noneconomic reasons, by political reasons such as antigovernment activities, this theory may not be suitable since social networks are hard to maintain under these circumstances.

\section{Related studies in China}

In recent years Chinese scholars have started to study domestic international immigration. Based on the concept of transnational social space advanced by Western scholars, Li et al. analyzed the mechanism in the formation of an African ethnic enclave on Xiaobei Road in Guangzhou City (Li et al. 2008, 2009) from the perspective of urban geography. Through observations, they confirmed that the residents' economic activities (procuring goods in Guangzhou and shipping them back to their departure country for sales) were all conducted within their own ethnic groups. Therefore, they proposed that the exportoriented economy of Guangdong Province was the external condition of their migration activities; the internal ethnic networks were the main form of its operation. The Xiaobei Road African ethnic enclave was a specially transplanted community. Similarly, the study of Xu (2009b) focused on the social networks of Africans. In order to reconstruct their networks for social support, Africans strengthened and reconstructed their social relations in Guangzhou. Xu points out that the core of their networks was the kinship ties based 
on emotional connections, whereas the external part was instrumental relationships based on interest exchanges. These studies seized on the key mechanism - social networks and social capital - but they focused only on the analyses of survival strategies and logic of Africans in China, and their analyses did not involve a more complete description of how this mechanism influences African immigrants' decision to leave or stay in China.

\section{Theoretical reflections and the advancement of research questions}

The phenomenon of transnational migration has occurred mainly in countries that were both immigration and developed countries. However, China is neither a nation of immigrants nor a developed country. This fact makes the previous macromigration theories that explain migration from underdeveloped countries to developed countries, or from labor-abundant countries to labor-shortage countries, no longer applicable to China's case. As a nonimmigration country, existing institutional arrangements in China generally do not allow domestic employment of a foreign workforce. It is thus difficult for neoclassical economic theory, human capital theory, and the new economics of migration theory to explain the perpetuation of the immigration of a large number of Africans who are now illegally dwelling and working in China.

The cumulative causation model proposes that the social networks of immigrants can self-evolve, accumulate, and cause potential immigrants to raise their expectations of migration returns. The theory has been confirmed by much empirical research on immigration phenomena in developed countries - one's tendency to immigrate is a function of the social environment in the sending country. Also, the subsequent flow of immigrants constantly strengthens the tendency toward future immigration. The cumulative causation theory proves that individuals' characteristics are much less important in predicting their tendency to immigrate compared to the social environment in the departure and destination countries. For the chronologically later choices to migrate, personal characteristics become increasingly unimportant.

This study therefore tests the effectiveness of cumulative causation theory through its application to the analysis of causal mechanisms of migration behaviors of African immigrants in China. Under the framework of this theory, this paper further aims to reveal the production logic of ethnic enclaves and these causal mechanisms.

\section{Methods}

\section{Data collection of African immigrants in Guangzhou City and Foshan City} The operationalization of the definition of African immigrants

Each year more than 300,000 foreigners from Africa pass through China or Guangdong Province. Among these, which migrants choose to settle there in the end? Since China is not an immigration country, very few foreigners receive long-term residence status. Consequently, it is impossible to operationalize the concept of 'immigrants' as whether or not one has gained such status in China.

Applicants for permanent residence mainly need to exhibit two prerequisites to qualify: time and desire, which generally require that applicants must have resided in their receiving country for a certain period when they apply and are willing to become naturalized (Xiao 2006). Therefore, in the operational definition of immigrants in this study, we regard illegal African foreign residents as 'international immigrants' in China. This definition is reasonable in that in a nonimmigration country, official 
mechanisms for identifying the legal status of migrants are nearly impossible. At any rate, the existence of immigration in China cannot be denied. Moreover, given the fact that China is a developing country, many foreigners who have been in China for a long time are not necessarily willing to accept long-term residence in China. Consequently, the measure of willingness cannot be confirmed simply by time. The operational definition that we choose here contains not only the dimension of time but also the dimension of willingness. ${ }^{\mathrm{a}}$

\section{Data collection}

In recent years there have been numerous reports about the settlement of Africans in Guangzhou and surrounding areas. A large number of Africans in Guangdong led to the 'three-illegals' problem, forcing Guangdong police to use a variety of means to govern them. Once identified as illegal residents in China, migrants would face heavy fines, repatriation, and even jail sentences. In addition, the dissemination of many negative news reports regarding Africans in Guangdong led to their exclusion by local residents. This also resulted in mutual distrust between African communities and the local authorities and residents in Guangdong (Li et al. 2009). This situation makes the study of African immigrants using traditional investigation methods very difficult and could even result in biased sampling groups.

(Heckathorn 1997) presented the respondent-driven sampling (RDS) method to deal with the survey of hidden and minority groups. Sociologically, this method is based on the basic principle that actors are all embedded in specific social networks. The RDS method improved the traditional snowball sampling method; its design of rolling recruitment in every wave of sampling satisfies the first-order Markov process. During this process, with the rapid convergence of Markov chains, a representative sample can be quickly obtained as soon as the sample attains equilibrium, on which researchers can make reliable inferences regarding the characteristics of populations. The RDS method has undergone several improvements (Heckathorn 2002, 2007; Salganik and Heckathorn 2004) and is now especially suited to sampling, analyzing, and studying sparse and hidden populations with unclear borders and scales, and anonymous identities (Zhao and Pedersen 2007).

Although the languages used in various African countries vary, the official languages are mainly English or French. Hence these are the languages adopted in our survey. ${ }^{\mathrm{b}}$ The first stage of RDS was the recruitment process to find seeds (the first-wave respondents). After finishing the survey of seeds, the seeds then recruited other eligible respondents for us, who would subsequently introduce new qualified respondents after completing their own questionnaires. Following this approach, the sample size increased like a rolling snowball. The survey of Africans residing in Guangzhou began on 10 July 2011 and ended on 6 August of the same year.

To motivate the recruiting of respondents and reduce the sampling bias, the RDS method adopted a dual-incentive strategy that provided material incentives for both respondents and recruiters. We awarded each recruiter 30 RMB (about 5 USD) to complete their own survey and 50 RMB (about 8 USD) for each respondent he/she recruited for us. Each respondent was given three coupons with which recruited respondents could participate in the survey. We repeated the above process until the sample size reached equilibrium and met our research demand. The longest 
recruitment chain in our sample reached the ninth wave; our final total was 656 respondents.

We carried out the RDS data collection method in two locations (location A and location B) where a large number of Africans gathered. Location A is a community in the center of the city. It is also a well-managed model community with developed commerce and convenient transportation facilities. Rent in this community is higher than that in nearby districts with a similar level of facilities; Africans who live in location A are mostly legal residents with relatively high economic capacities. Location B, established 20 years ago, is a run-down community. It is located in the semiurban area. The rental cost in location B is very low - only about one third of that in location A. Governmental departments supervise location B more loosely. As an investigation involving illegal residents, this study handled the research ethics issue carefully. ${ }^{c}$ Figure 1 shows the two RDS recruitment chains at the two survey locations.

There are two kinds of dots in Figure 1 that represent the respondents - solid dots and hollow dots. Solid dots represent legal residents and hollow dots represent illegal residents. The figure shows that location A contained fewer illegal residents compared to location $\mathrm{B}$, where a large number of illegal residents reside. The figure also shows that the networks of Africans in location B were relatively more developed with longer recruitment chains. The success rate of recruitment in location B was also higher.

The RDS methods resulted in two different patterns of recruiting chains in these two locations. Specifically, Africans in location A had a relatively lower density of social networks in comparison with that in location B. Eighty-nine respondents $(25.5 \%$ of total respondents in location A) did not help us recruit new respondents, while only fourteen respondents in location B (4.5\%) did not help.

\section{Basic characteristics and an exploratory description of African immigrants in Guangzhou}

Since this study obtained samples by the RDS method, we corrected the selection bias caused by the recruitment process according to the combination of iteration of transformation matrices between different rounds of recruitments and the size of each individual's network. Finally, we were able to characterize the features of this population. The detailed formula can be checked in Salganik and Heckathorn (2004) and Goel and Salganik (2009). This study used the commands from STATA software that was specifically designed to analyze the data obtained by the RDS method (Schonlau and Liebau 2012).

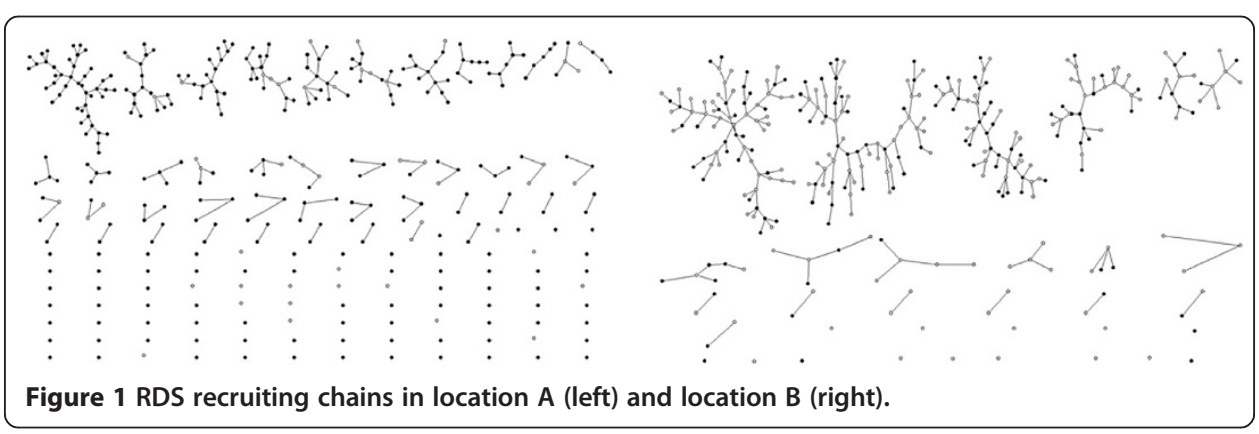




\section{Geographical distribution}

We analyzed the proportions of illegal African immigrants by different places of origin (Table 1). Nearly $70 \%$ came from Western Africa. ${ }^{\mathrm{d}}$

\section{Basic characteristics of the sample}

Table 2 gives the basic characteristics of the sample and the inference of total demographic characteristics through the RDS method. We can roughly describe the characteristics of Africans in Guangzhou as mainly young migrants, a lower proportion of women than men, mainly from Western Africa, nearly 40\% were illegal residents, most entered China with business visas, 82\% spoke English and 18\% spoke French, and most had a high school level of education or above.

\section{The migration-hazard function}

Based on our previous analysis, we propose that when considering a nonimmigration country, we should operationalize the definition of 'migrants' by whether or not they have the status of illegal residence. Thus, when studying the transition of Africans' identities from legal residents to illegal residents, we can take it as an 'event' whose state shifted from one to the other. The event in this paper refers to the occurrence of deterministic migration behaviors. Therefore, we adopted the event history model to analyze the migration-hazard function.

In our estimation we assume that all independent variables are temporarily zero (Kallbfleisch and Prentice 1980). We also do not assume a fixed time distribution of continuous legal residence because we did not have any prior knowledge of behavior patterns of illegal migrants in a nonimmigration country; that is, when other factors are controlled, there will not be an exact functional relationship between the time and the risk of illegal residence. We thus adopted the Kaplan-Meier method, a nonparametric method of estimation that does not assume a certain distribution of data.

The survival function indicates the probability of an observed object whose surviving time surpasses a certain moment. It presents the gradually increasing possibility of illegal residence status of an African as the time they live in China lengthens. At the point of time that he/she has just arrived in Guangzhou, his/her survival rate as a legal resident is 1 . However, as time goes by, the phenomenon of illegal residence starts to occur and the rate of legal residence shows a clear downward trend over time. As a consequence, the survival function decreases monotonously and exhibits an asymmetric skewed distribution. Using the Kaplan-Meier method, the distribution of survival probability to the length of time since one had first arrived in China was calculated and is shown in Figure 2 (left).

Figure 2 shows two characteristics. First, there is a substantially steep drop phase in the first 12 months, indicating that a considerable number of Africans chose illegal

Table 1 Demographic features of regional distribution by RDS inference ( $N=656, \%)$

\begin{tabular}{llll}
\hline Region & Legal residence & Illegal residence & Total \\
\hline Eastern Africa & 21.13 & 3.95 & 10.5 \\
Southern Africa & 15.69 & 6.08 & 7.1 \\
Western Africa & 35.29 & 76.90 & 69.6 \\
Central Africa & 27.89 & 13.07 & 12.9 \\
Total & 100 & 100 & 100 \\
\hline
\end{tabular}


Table 2 Basic features of the sample and demographic features obtained by RDS inference $(N=656)$

\begin{tabular}{|c|c|c|c|c|c|c|c|}
\hline \multicolumn{2}{|l|}{ Variables } & \multicolumn{2}{|c|}{ Proportion (\%) } & \multicolumn{2}{|l|}{ Variables } & \multicolumn{2}{|c|}{ Proportion (\%) } \\
\hline & & & & & & & \\
\hline Gender & Male & $\begin{array}{l}\begin{array}{l}\text { Point } \\
\text { estimation }\end{array} \\
80.7\end{array}$ & $\begin{array}{l}\text { RDS } \\
\text { estimation } \\
66.7\end{array}$ & Language & English & $\begin{array}{l}\begin{array}{l}\text { Point } \\
\text { estimation }\end{array} \\
72.68\end{array}$ & $\begin{array}{l}\begin{array}{l}\text { RDS } \\
\text { estimation }\end{array} \\
81.73\end{array}$ \\
\hline & Female & 19.3 & 33.3 & & French & 27.31 & 18.26 \\
\hline \multirow[t]{5}{*}{ Education } & Illiterate & 0.6 & 2.4 & Age & 10 to 19 & 0.5 & 0.4 \\
\hline & $\begin{array}{l}\text { Elementary } \\
\text { school }\end{array}$ & 3.8 & 6.6 & & 20 to 29 & 39.7 & 38.4 \\
\hline & Middle school & 19.5 & 21.2 & & 30 to 39 & 47.6 & 44.5 \\
\hline & High school & 28.3 & 31.6 & & 40 to 49 & 10.6 & 12.3 \\
\hline & $\begin{array}{l}\text { College } \\
\text { and above }\end{array}$ & 47.8 & 38.2 & & 50 and above & 1.6 & 4.4 \\
\hline \multirow{4}{*}{$\begin{array}{l}\text { Regions } \\
\text { of origin }\end{array}$} & East & 15.4 & 10.5 & Visa type & Tourist & 15.7 & 14 \\
\hline & South & 14 & 7.1 & & Business & 75.8 & 78 \\
\hline & West & 45.8 & 69.6 & & Working & 1.7 & 1.2 \\
\hline & Central & 24.8 & 12.9 & & Student & 6.8 & 6.6 \\
\hline \multirow{3}{*}{$\begin{array}{l}\text { Residence } \\
\text { status }\end{array}$} & Legal & 65.4 & 60.7 & \multirow{3}{*}{$\begin{array}{l}\text { Length of stay } \\
\text { in China (years) }\end{array}$} & 1995 to 2007 & 18.1 & 21.2 \\
\hline & Illegal & 34.6 & 39.3 & & 2008 to 2009 & 28.2 & 30.3 \\
\hline & & & & & 2010 to 2011 & 53.5 & 48.5 \\
\hline
\end{tabular}

residence right after they arrived in China. ${ }^{\mathrm{e}}$ Second, there is a greater downward trend of the slope of the survival function in the late stage, at the time point of around 40 months.

In order to show the invisible information of the survival function more clearly, a hazard ratio estimation of illegal residence is drawn to describe the probability of illegal residence of Africans in Guangzhou at each time point (see Figure 2, right-hand side). Generally speaking, the risk of illegal residence exhibits a U-shaped structure. The probabilities of turning to illegal residence vary at different time points. The probability of becoming an illegal resident at early stages is very high, then the probability of illegal residence declines but again starts to rise intermittently 3 years later. Qualitative interviews indicate that this was because the costs of legal residence are more expensive than that of illegal residence. After more than 3 years in China, they had adapted to

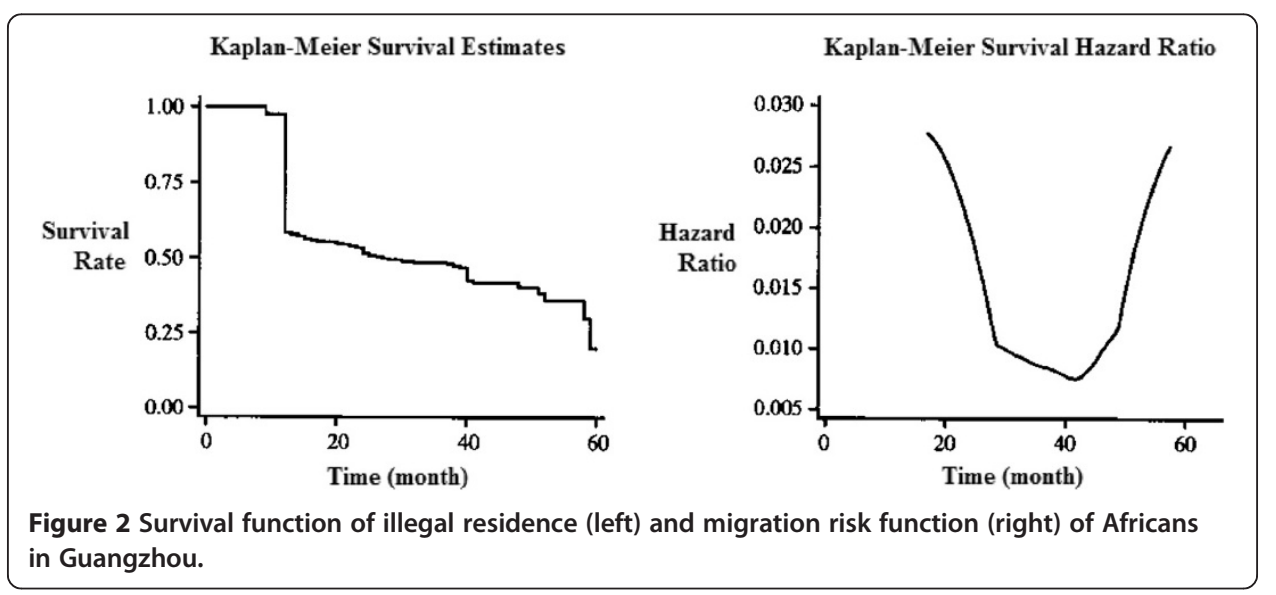


their life in China and their living and work had been established in China. They therefore chose to be an illegal migrant at this time, which was a rational choice. A search through the study of the migration-hazard function in international academics shows that there is only a monotonically decreasing form of function between the risk of migration and the duration of stay. We have not found any report that obtained a $\mathrm{U}$-shaped function of migration risk as we have in this study. It should be noted that this is a peculiar migration risk function pattern that only appears in a nonimmigration country. ${ }^{\mathrm{f}}$

\section{Preliminary evidence of cumulative casual effects}

(Massey 1990a, b) regarded transnational migration as a dynamic and self-reinforcing process. The effect of immigrants' networks on reducing the cost of migration became increasingly stronger as time went by, which finally helped people from lower and lower classes to migrate. He examined the migration of Mexican immigrants to the USA and found that the decline of class over time, predicted by his own theory, was confirmed. It can be inferred that if the theory of cumulative causation could correctly describe the mechanism of actions in an early stage of Africans' immigration to Guangzhou, the increase in the effects of network relationships could be observed, and the cost of migration would decrease as time went by. The class background of Africans who immigrated to Guangzhou continued to decrease.

Social capital and evidence of its increasing effect The following core measures of social capital for ethnic economics and ethnic residence significantly increased: whether one had anyone to help with his/her reception when entering China and the number of acquaintances from one's motherland. The consequences of migration as well as the effects of cumulative causation that led to the continuous occurrence of future migration - whether one had improved the economic status of relatives in one's homeland and whether one had brought relatives or friends to China - also increased significantly. Additionally, the agency fees for applying for a visa extension decreased, which shows that social networks can effectively reduce the cost of migration (see Figures 3,4,5,6).

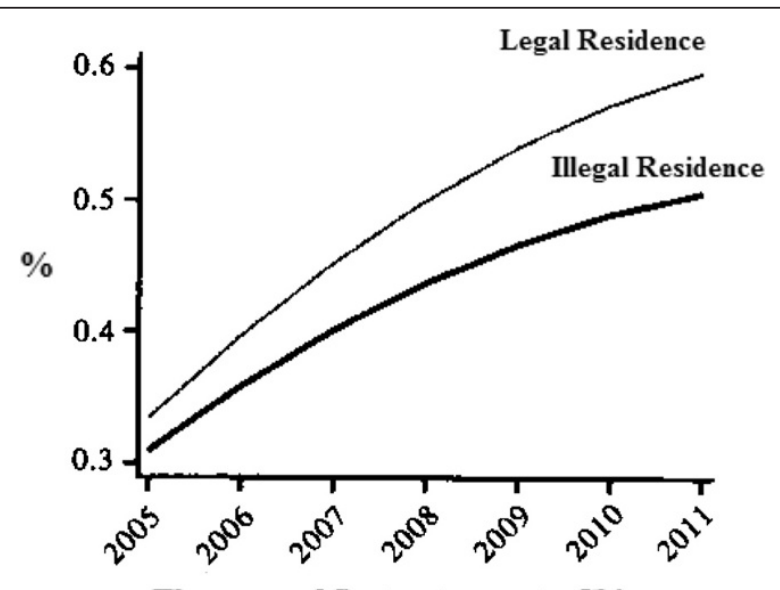

The year of first entrance to China

Figure 3 Distribution of social capital (proportion of Africans who have people helping with their reception). 


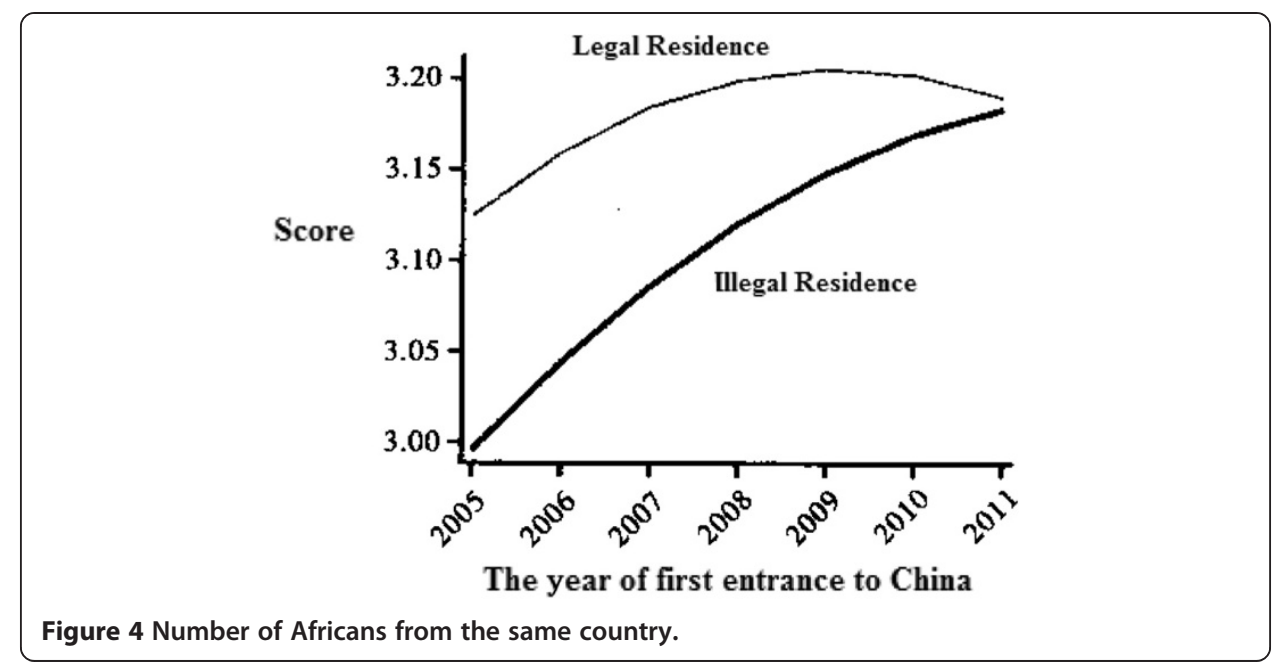

The effect of declining class background during migration The phenomenon of class decline predicted by the theory of cumulative causation was observed. Whether choosing legal residence or illegal residence, immigrants' risks and costs of coming to China declined as social networks continued to expand, leading to the continuous decline of social classes of African immigrants (see Figures 7,8,9,10,11,12).

The research hypotheses and data analysis Hypotheses

According to the explorative descriptions above, we have basically confirmed that African foreigners in Guangzhou were still in their early stages of immigration. The predicted effects by the cumulative causation theory of migrants - both the class decline effect and the cumulative effect of social networks - can be observed in the collected sample. To further analyze the specific role and function of cumulative causation theory on African

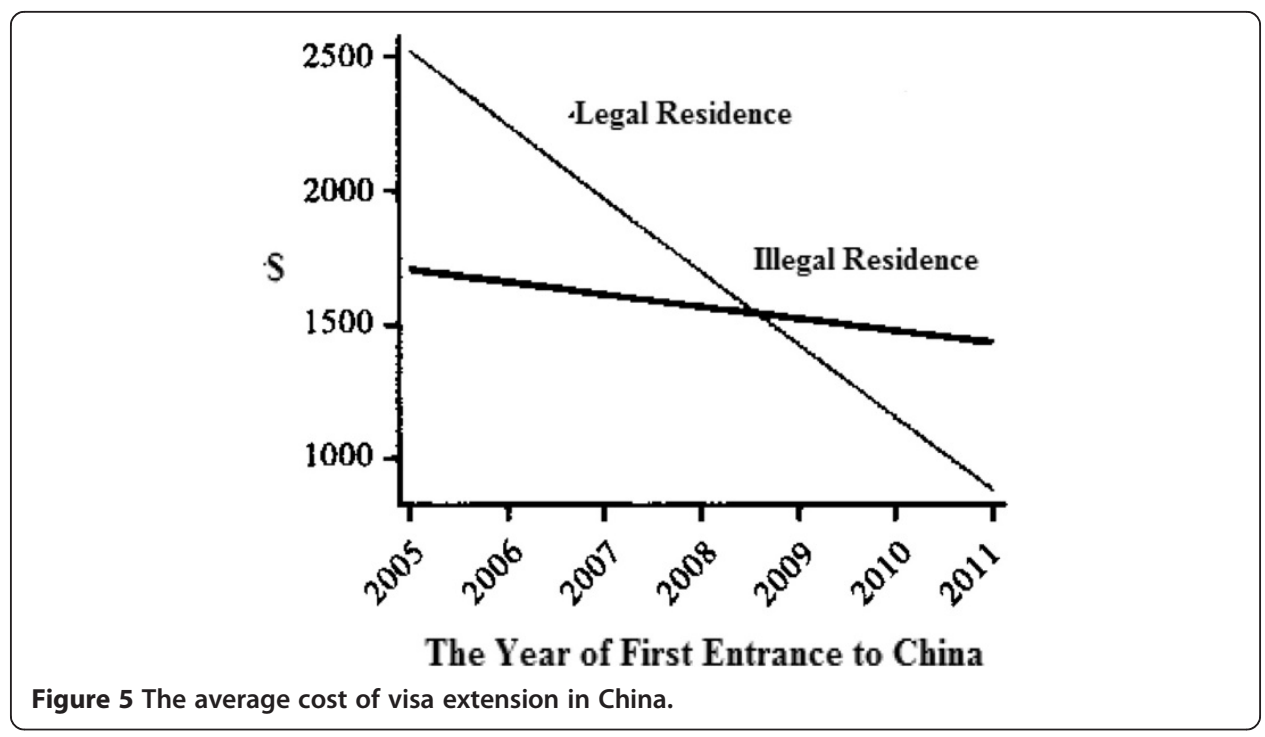




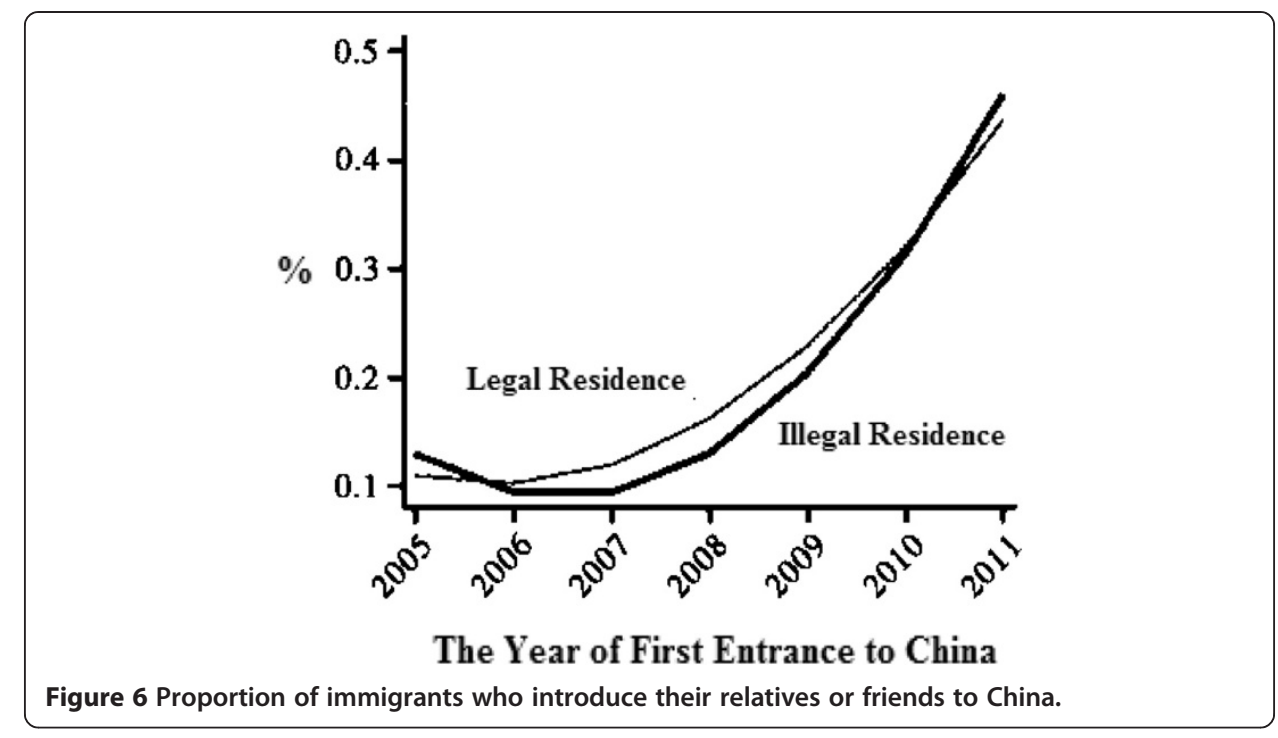

immigrants in Guangzhou, Massey's research is used to advance the research hypotheses from the two perspectives of human capital and social capital.

In general, neoclassical economics often predicts that human capital can increase the probability of international migration. However, a number of scholars who have studied Mexican immigrants in the USA found that for illegal immigrants, the influence of their human capital measured in forms of education was negative toward the choice of migration (Massey et al. 1987; Taylor 1986, 1987; Borjas 1994). Regardless of how high their education level was in their original country, illegal immigrants' diplomas could not help them smoothly find a high-paying job in the early stage of their immigration; they had no choice but to perform low-skilled jobs. Since China is a nonimmigration country, there is no space for the domestic labor market to absorb international immigrants. Illegal African immigrants thus will not be able to find ideal jobs with their diplomas. The human capital measured by education level does not help increase the possibility of immigration. Considering the generally low education

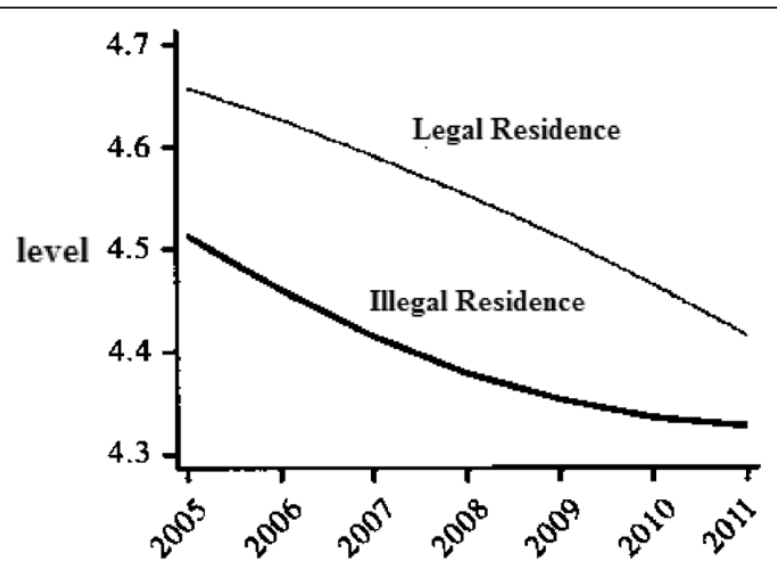

The Year of First Entrance to China

Figure 7 Education level. 


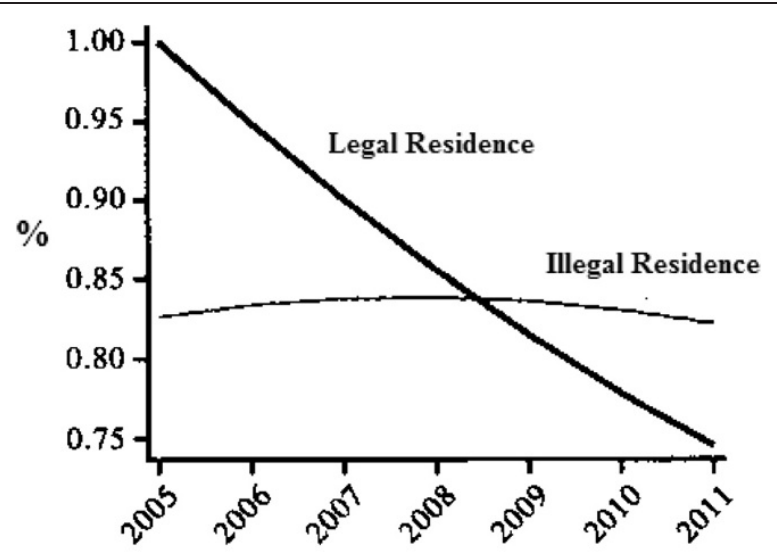

The Year of First Entrance to China

Figure 8 Immigrants having family members who are living oversea or have working experience.

levels of African foreigners in Guangzhou, we propose a hypothesis of general human capital (education):

Hypothesis 1.1. Ineffectiveness of general human capital: With the continuation of the migration process, general human capital gradually loses its predictive power in migration behaviors.

In addition to general human capital such as education, a special form of human capital exists, namely, migration-specific human capital. This consists of two aspects - one is human capital during the process of migration, which means the ability to grasp knowledge and information from sending countries; the other is the destination-specific human capital proposed by (Chiswick 2008), which mainly refers to the grasping of information and knowledge of living and work that immigrants need after their arrival at a destination country. ${ }^{g}$ Clearly, these two kinds of migration-specific human capital may have different

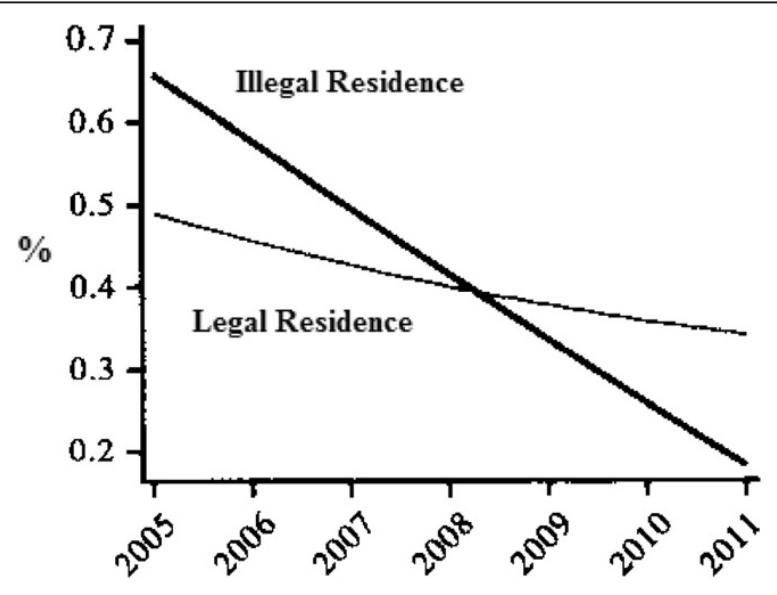

The Year of First Entrance to China

Figure 9 Immigrants with family members who are living or have working experience in China. 


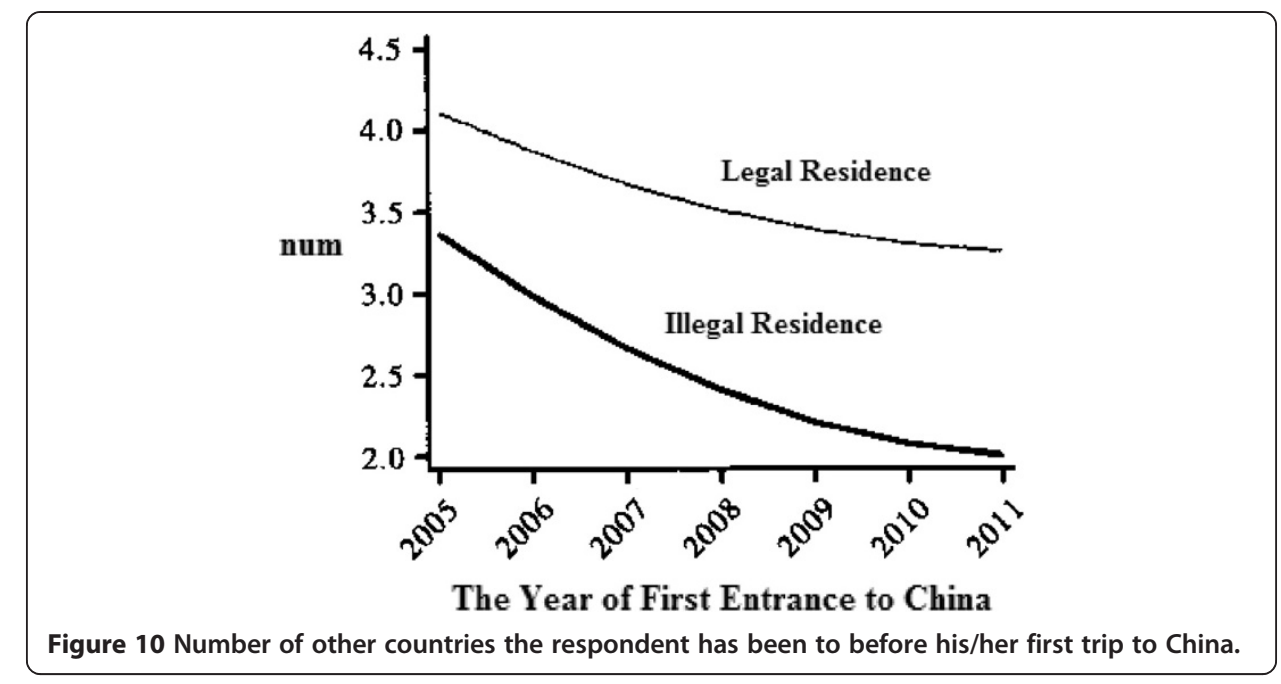

influences on migration behavior compared to the general human capital. The following hypothesis is thus made:

Hypothesis 1.2. Effectiveness of migration-specific human capital: As the migration process continues, migration-specific human capital still has the predictive power for migration behaviors.

As has already been preliminarily confirmed, the effectiveness of the social networks of African immigrants in Guangzhou, especially illegal residents, keeps increasing, while the migration costs and social classes of new immigrants from the home country continue to decrease. Cumulative causation theory is a good tool for analyzing the mechanism of immigration to China; however, since China is a nonimmigration country, Africans need to go through several stages before they decide to illegally reside in Guangzhou. First, potential migrants need to have the ability to obtain knowledge and information about China through their individual social networks in their home country;

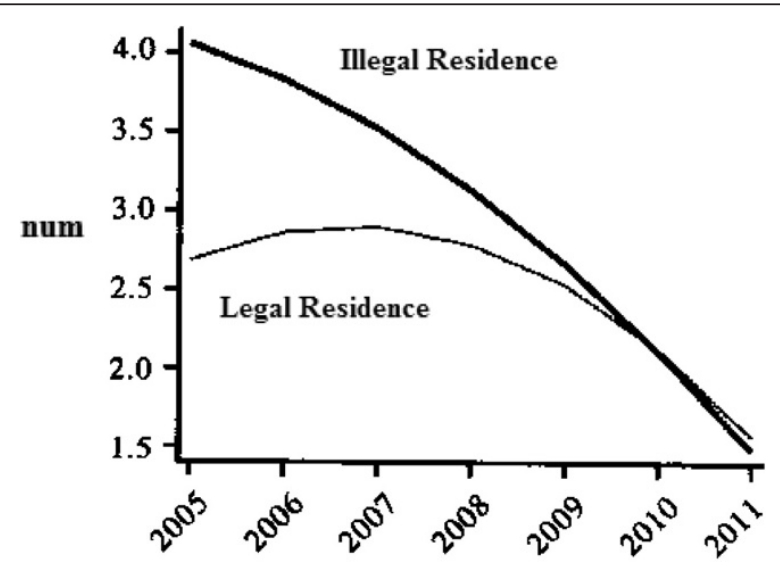

The Year of First Entrance to China

Figure 11 Number of cities the respondent has been to before coming to Guangzhou, China. 


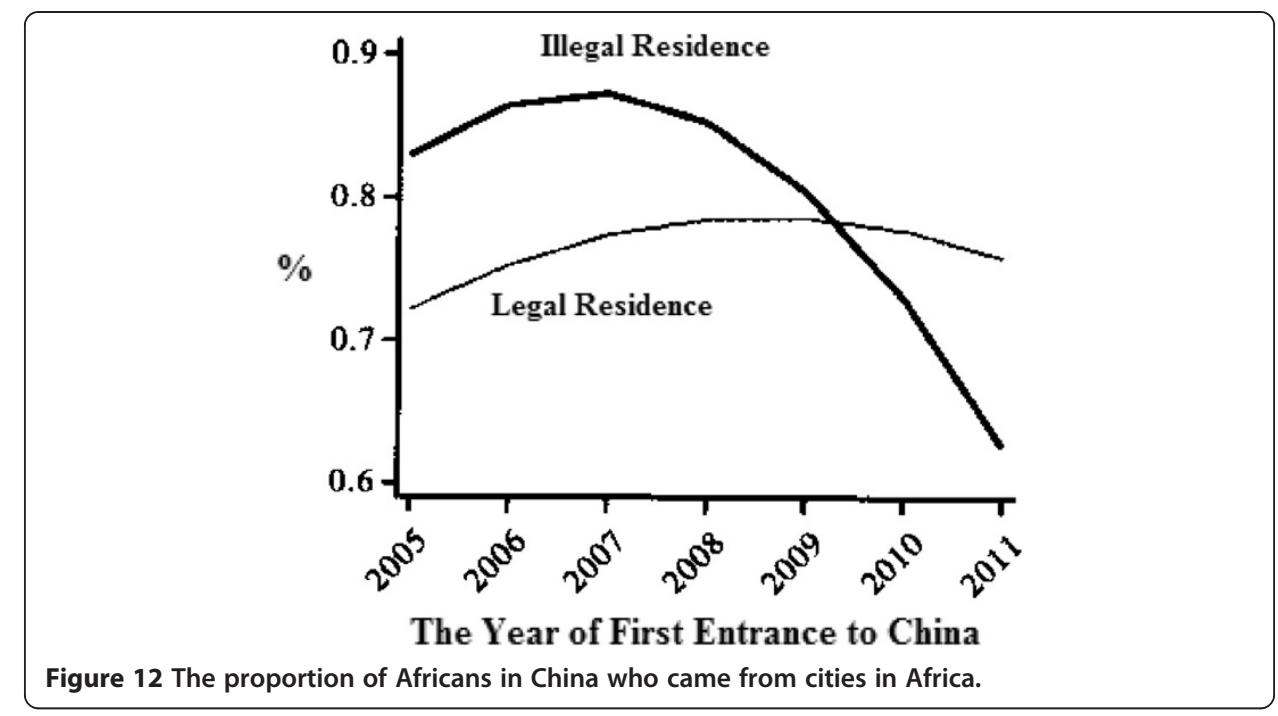

second, local social networks have to be transnational networks that are able to connect the sending and receiving countries. These networks will help them reduce migration costs. These networks will obviously have a crucial influence on potential immigrants' migration decisions, as well as whether they can easily adapt to the new society after their arrival. Moreover, the existence of transnational social networks may ultimately have a strong impact on the migrants' decision to be illegal or not.

Massey's 1994 study does not distinguish between the above processes; his social capital measured only an individual's social capital (whether one's parents, brothers, or sisters had migrated to a destination country) and the social capital of the sending community (the proportion of people in a community who have migrated to a destination country). Since China is a nonimmigration country, social capital at the destination is important for Africans' decision on illegal residence.

The existing literature suggests that people from communities with high mobility have a higher possibility to migrate compared to those from low-mobility communities. The reason is that migration networks at the community level can support potential migrants by providing them with information about migration processes, jobs at destinations, renting, and so on. The cumulative causation theory was developed from a longer-term perspective in analyzing the migration process, while China is still at its initial stage. This study finds that cumulative causation theory describes this process with a subtler evolution. In the early stages of migration, immigrants could successfully immigrate only if they could obtain help through strong ties in their immigration networks, but with the passage of time and as immigration networks in sending societies are increasingly developed, people can get assistance to help them achieve migration even from weak ties. Consequently, social capital at the individual level has less predictive power in one's possibility of migration over time. At the same time, the predictive power of social networks at the community level of the sending society becomes stronger and stronger.

Since illegal immigration to China has severe legal consequences and dismal outcomes, ${ }^{\mathrm{h}}$ potentially illegal immigrants must have greater confidence under those external constraints. Actually, only the immigration networks at destinations can provide 
newcomers with that kind of knowledge and information. According to the cumulative causation theory, the longer one resides in a destination country, the better one can understand the information, rules and regulations, and potential loopholes in that country's enforcement. It can thus be assumed that communities' social capital at the destination will have an increasingly predictive power on one's migration behavior. This leads to the following three hypotheses:

Hypothesis 2.1. The ineffectiveness of individual social capital: As the process of migration continues, the social capital of individuals gradually loses its power to predict migration behaviors.

Hypothesis 2.2. The effectiveness of community-level social capital in the departure country: As the migration process continues, the external social capital of communities in the sending society still has predictive power for migration behaviors.

Hypothesis 2.3. The effectiveness of community-level social capital in the receiving community: As the migration process continues, the external social capital of migrants in communities in the receiving society still has predictive power for migration behaviors.

Since China is still a developing country, the more economic capital an African has, the lower the possibility that he or she will migrate to China. The third hypothesis addresses the negative function of the economic capital:

Hypothesis 3. The negative function of economic capital: The more economic capital one has, the lower the probability that one will migrate.

\section{The discrete event history model and its application to RDS analysis}

We use months as the time interval in our observation. In each discrete time period (every month), we use one dummy variable to identify the occurrence of the event, illegal or not. Discrete time segments are accumulated until the event occurs or is halted; through this we obtain pooled data. Such data can be analyzed with models analyzing dummy variables; all time-varying and nontime-varying variables can be easily placed in that model (Singer and Willett 2003). The model used here is an approximate of the hazard rate because the dependent variable in our model is not hazard rate but odds ratios, which are function of time and other variables.

Since RDS data was collected through a revised snowball sampling method based on respondents' social networks, here, a multilevel event history model was adopted to further confirm our assumptions. In real-life situations people come from different groups of networks, such as an ethnic group in Nigeria, a Christian group, and a group of hardware merchants. Bounded by the RDS sampling method, individuals who belong to the same group as his/her recruiter have a higher probability of being recruited. Therefore, by this method each recruitment group embodies its inherent homophily of a social network, thus leading to the existence of unobservable common characteristics among group members. ${ }^{\mathrm{i}}$ A multilevel model is necessary to eliminate the bias caused by the dependent covariance in these recruitment networks. Moreover, since the model was set to study the relationships between individual characteristics (the dependent variable and independent variables), according to the analytical principle advanced by 
Christopher and Larry (1994), whether a weighted model or an unweighted model is used will result in consistent and unbiased estimates of standard errors if the occurrence of a case is a function of independent variables. Thus, to revise the model, we mainly used the probability of the occurrence of the dependent variable, which is actually the different probabilities of the occurrences of a legal resident and an illegal resident in the sample. ${ }^{j}$

The concept of 'the risk of immigration (illegal residence)' was introduced; a higher-risk level means the possibility of migration (illegal residence) is higher and vice versa. We set a random intercept multilevel model as follows:

$$
\begin{aligned}
\log i t\left[h_{x}\left(t_{i j}\right)\right]=\log _{e}\left[\frac{h_{x}\left(t_{i j}\right)}{1-h_{x}\left(t_{i j}\right)}\right] & =\beta_{o i}+\beta_{1} x_{1 i}+\beta_{2} z_{2 i}+\beta_{31} t_{i j}+\beta_{32} t^{2}{ }_{i j}+\beta_{33} t^{3}{ }_{i j} \\
& \beta_{o i}=y_{00}+\delta_{o i} \\
& \beta_{1}=y_{1} \\
& \beta_{2}=y_{2} \\
& \beta_{31}=y_{31} \\
& \beta_{32}=y_{32} \\
& \beta_{33}=y_{33} \\
& \delta_{o i} \sim N\left(0, \delta_{u}{ }_{u}\right)
\end{aligned}
$$

Here the occurrence pattern of hazard or conditional event probability of an event at time $t$ is analyzed. The random intercept model means that the baseline logit hazard of different groups has random variations. A more complicated random-coefficient model was not set because the numbers of cases in some groups were too small to conduct a random coefficient analysis. From the perspective of the multilevel model, this study uses a two-level random intercept model; Gelman and Hill (2007) proposed that the minimum requirement of a two-level random intercept model is two observational sets. The second reason is that this is the first time such a study was conducted in China; the construction of a more complicated causal relationship needs further in-depth analysis and discussion.

\section{Results and discussion}

To verify the hypotheses of this research, time and demographical variables were used as controlled variables. Since the analysis above has found the existence of turning points of time, we introduced a cubic item of time and further added individual's gender and age. As an indicator of general human capital, education was introduced with five levels ranging from illiteracy to bachelors degree. Since Africans are in China mainly for trade, we introduced a dummy variable of whether one conducted business before coming to China as a measurement of general human capital. Regarding migration-specific human capital, the number of countries that one had visited before coming to China was introduced, as well as the number of cities in China that one had visited before coming to Guangzhou. Chinese proficiency was measured as one's human capital at the destination. For economic capital we introduced the scales of departure cities, GDP per capita of one's home country, and whether one had a house or investment in one's hometown. For individual-level social capital, we introduced the measure of family members of respondents - whether they had any experience with international migration and whether they had any experience of travel to China. We also measured 
the number of acquaintances in Guangzhou - number of compatriots, number of noncompatriot Africans, number of Cantonese, and whether one had acquaintances to help with reception when one first arrived in Guangzhou. The community-level social capital in sending countries comprises the following items: whether moving to China has become a habitus (the proportion of illegal immigrants that are from the same country as the respondent) and the social atmosphere of communities in the departure country - whether many local people are going to China and whether immigration to China has improved the lives of people in the departure country. The social capital of destinations is measured by the number of compatriot and noncompatriot Africans in one's living community.

This study adopts nested models to verify the validity of the above assumptions: Model 1 is the base model in which independent variables consist of background variables, demographic variables, general human capital variables, and economic capital variables. Model 2 adds migration-specific human capital variables to the base model. Model 3 further adds individual-level social capital variables to model 2. Model 4 further adds community-level social capital variables to model 3. During periods of financial crisis and the Beijing Olympic Games in 2008, the Asian Games in 2010, and the World University Games in 2011, there were higher standards of social safety in China. Immigrants thus faced different institutional situations and economic environments before and after 2008. Therefore, different logic might exist for explaining the actions of immigrants. This study regards Africans coming to China before 2008 and those after 2008 (including the year 2008) as two different groups and analyzes them in different models. The results are shown in Table 3.

The hypotheses about human capital are discussed first. With regard to the prediction of illegal immigration behaviors of Africans, the effect of general human capital is very low. Although in model 4 the variable of whether or not one conducted business before coming to China had some effect, it was not significant among Africans who came in or after 2008. Therefore Hypothesis 1.1 has been verified. However, migrationspecific human capital is effective in the models, but its mechanism differed from the assumptions. The number of countries one had visited before one came to China was negatively related to the possibility of illegal migration behavior, which means that China, as a developing and nonimmigration country, is not the most preferred destination of immigration for Africans. The number of Chinese cities one had visited before one came to Guangdong had conflicting effects before and after 2008: before 2008 it was positively related to the possibility of illegal residence, while the effect was the opposite in and after 2008. This illustrates the idea that the legal enforcement in Guangzhou was harsher than in any other mainland China cities since then, and thus people who have visited other cities tend to not choose illegal immigration to Guangzhou. In conclusion, people with more migration-specific human capital are less likely to come to China and Guangzhou. This conclusion opposes past immigration theories. Since most past immigration studies analyzed immigration countries, this new phenomenon observed in a nonimmigration country is reasonable.

The hypothesis that economic capital is negatively related to illegal immigration behaviors has also been supported. What is particularly interesting is the fact that whether one had investments in one's hometown before leaving affected one's migration behavior: after 2008 its negative effect disappeared, indicating that Africa's own economic 
Table 3 Multi-level event history models of African immigration to Guangzhou

\begin{tabular}{|c|c|c|c|c|c|c|c|c|}
\hline \multirow[t]{2}{*}{ Variables } & \multicolumn{2}{|l|}{ Model 1} & \multicolumn{2}{|l|}{ Model 2} & \multicolumn{2}{|l|}{ Model 3} & \multicolumn{2}{|l|}{ Model 4} \\
\hline & Before 2008 & After 2008 & Before 2008 & After 2008 & Before 2008 & After 2008 & Before 2008 & After 2008 \\
\hline \multicolumn{9}{|l|}{ Time variables } \\
\hline Length of time spent in China & $0.136^{* * *}$ & $0.148^{* * *}$ & $0.1336^{* * *}$ & $0.146^{* * *}$ & $0.1309^{* * *}$ & $0.142^{* * *}$ & $0.147^{* * *}$ & $0.125^{* * *}$ \\
\hline Square of length of time in China & $-0.00236^{* * *}$ & $-0.00300^{* * *}$ & $-0.000532^{* * *}$ & $-0.00295^{* * *}$ & $-0.000478^{* * *}$ & $-0.00293^{* * *}$ & $-0.00017^{* * *}$ & $-0.00251^{* * *}$ \\
\hline Cube of length of time in China & $9.34 \mathrm{e} 06^{* * *}$ & $1.23 \mathrm{e} 05^{* * *}$ & $2.25 \mathrm{e} 06^{* * *}$ & $1.21 \mathrm{e} 05^{* * *}$ & $1.88 \mathrm{e} 06^{* * *}$ & $1.20 \mathrm{e} 05^{* * *}$ & $-7.03 e 06^{* * *}$ & $1.02 \mathrm{e} 05^{* * *}$ \\
\hline \multicolumn{9}{|l|}{ Background variables } \\
\hline Age & -0.00188 & 0.00459 & 0.00157 & 0.0102 & 0.007 & 0.00989 & -0.0263 & 0.0102 \\
\hline Gender $($ male $=1)$ & 0.532 & 0.253 & 0.334 & 0.429 & 0.42 & 0.403 & $2.670^{* *}$ & 0.469 \\
\hline \multicolumn{9}{|l|}{ General human capital } \\
\hline Education level & -0.0791 & -0.117 & -0.182 & -0.0308 & -0.193 & -0.0705 & 0.0127 & -0.0986 \\
\hline Conducted business before coming to China & -0.428 & -0.157 & -0.292 & -0.247 & -0.403 & -0.324 & $-1.035^{*}$ & -0.38 \\
\hline \multicolumn{9}{|l|}{ Economic-specific human capital } \\
\hline Come from big city $(=1)$ & 0.646 & -0.402 & 0.513 & -0.329 & 0.53 & -0.318 & 0.405 & -0.283 \\
\hline Have house in sending country $(=1)$ & -0.422 & -0.357 & -0.463 & -0.26 & -0.511 & -0.244 & -0.792 & -0.208 \\
\hline Have investment in sending country $(=1)$ & $-0.939^{* * *}$ & -0.397 & $-0.814^{* *}$ & -0.328 & $-0.906^{* *}$ & -0.246 & $-0.685^{* * *}$ & -0.267 \\
\hline GDP per capita of sending country & $-0.000769^{*}$ & -0.00022 & $-0.000813^{*}$ & -0.00025 & $-0.000797^{*}$ & -0.000224 & $-0.000423^{* *}$ & $-0.000337^{*}$ \\
\hline \multicolumn{9}{|l|}{ Migration-specific human capital } \\
\hline Chinese language level & & & 0.00197 & -0.139 & 0.00823 & -0.144 & 0.464 & -0.111 \\
\hline Number of countries visited before China & & & $-0.169^{*}$ & $-0.257^{* * *}$ & $-0.167^{*}$ & $-0.226^{* * *}$ & $-0.277^{* *}$ & $-0.150^{*}$ \\
\hline The number of cities been to before Guangzhou in China & & & $0.213^{* * *}$ & $-0.098^{* *}$ & $0.210^{* *}$ & $-0.0724^{* *}$ & $0.216^{* *}$ & $-0.043^{* *}$ \\
\hline \multicolumn{9}{|l|}{ Social capital at individual level } \\
\hline Whether family members have oversea working or living experience & & & & & 0.448 & -0.0765 & 0.0023 & -0.208 \\
\hline Whether family members have working or living experience in China & & & & & 0.039 & $-0.538^{* *}$ & $0.0719^{*}$ & $-0.370^{* *}$ \\
\hline The number of Cantonese you know in China & & & & & -0.00312 & 0.00167 & -0.0014 & 0.00241 \\
\hline
\end{tabular}


Table 3 Multi-level event history models of African immigration to Guangzhou (Continued)

\begin{tabular}{|c|c|c|c|c|c|c|c|c|}
\hline The number of compatriot you know in China & & & & & -0.000723 & $0.00732^{* * *}$ & 0.00251 & $0.00889^{* * *}$ \\
\hline The number of non-compatriot Africans you know in China & & & & & -0.000319 & $0.00741^{* *}$ & 0.0945 & $0.659^{* * *}$ \\
\hline Have acquaintances help with the reception & & & & & $0.317^{*}$ & $0.0579^{*}$ & $0.448^{* *}$ & $0.252^{* *}$ \\
\hline \multicolumn{9}{|l|}{ Social capital at the community level } \\
\hline The proportion of illegal Migrants among your compatriots & & & & & & & $3.48^{* *}$ & $1.062^{* *}$ \\
\hline Are there many people from your homeland coming to China & & & & & & & $0.327^{* * *}$ & $-0.600^{* *}$ \\
\hline $\begin{array}{l}\text { Whether immigration to China has improved the lives of } \\
\text { people at your homeland or not }\end{array}$ & & & & & & & $1.461^{* * *}$ & 0.0311 \\
\hline Number of Africans in the community you live & & & & & & & 0.00406 & $0.00893^{* *}$ \\
\hline Number of compatriot in the community you live & & & & & & & 0.00351 & $0.440^{* * *}$ \\
\hline Constant & $-2.350^{* *}$ & $-4.90^{* * *}$ & $-2.885^{* *}$ & $-4.20^{* * *}$ & $-2.884^{* * *}$ & $-4.85^{* * *}$ & $-3.641^{* * *}$ & $-4.001^{* * *}$ \\
\hline \multicolumn{9}{|l|}{ Random effects } \\
\hline Recruit group level & $1.027^{* * *}$ & $1.371^{* * *}$ & $0.9623^{* * *}$ & $1.257^{* * *}$ & $0.9877^{* * *}$ & $1.318^{* * *}$ & $0.651^{* * *}$ & $1.248^{* * *}$ \\
\hline Individual residual & $1.541^{* * *}$ & $1.446^{* * *}$ & $1.2445^{* * *}$ & $1.368^{* * *}$ & $1.050^{* * *}$ & $1.196^{* * *}$ & $0.949^{* * *}$ & $1.022^{* * *}$ \\
\hline Log likelihood & -265.48 & -726.05 & -243.99 & -718.07 & -242.72 & -710.8 & -211.87 & -623.719 \\
\hline Observations (individual $\times$ month) & 6,867 & 7,924 & 6,867 & 7,924 & 6,867 & 7,924 & 6,867 & 7,924 \\
\hline Number of groups & 51 & 108 & 51 & 108 & 51 & 108 & 51 & 108 \\
\hline Number of observing sample & 116 & 511 & 116 & 511 & 116 & 511 & 116 & 511 \\
\hline
\end{tabular}

${ }^{* * *} p<0.01,{ }^{* *} p<0.05,{ }^{*} p<0.1$. 
situation was also deteriorating. Even people who had investments in their hometowns had the same willingness to migrate to China as those who had no investments. This implies that Africans' willingness to come to China was determined not only by the economic and institutional environments in their living communities in China but also by situations in Africa.

However, individual-level social capital variables were partially significant and their direction did not violate the accumulative causation theory. The comparison between model 3 and model 2 shows that these variables may help us better understand immigration behaviors of Africans in China. The likelihood ratio tests show that the value of likelihood ratio in the models with respondents who came to China before 2008 increased only 1 unit of likelihood from model 2 to model 3, which is not a significant improvement. In the post-2008 (including 2008) model, the likelihood ratio increased 8 units between the two models, which also shows little apparent improvement. These results validate the hypothesis that the individual social capital is not effective.

Different from the ineffectiveness of individual-level social capital variables, the introduction of community social capital variables in the different models significantly improved the fit of the models. By introducing them, model 4 improved 31 units of likelihood in the pre-2008 model and 87 units of likelihood in the post-2008 model, compared to model 3 . The community-level social capital variables showed multiple effects. The first is that community-level social capital had a positive effect before 2008. Specifically, the proportion of illegal immigrants in one's community of departure had a significant positive effect on the action of one's immigration. However, after 2008 the effects of the two variables indicating the social atmosphere in the departure country disappeared and even became negative. This shows that the difficult situation of African immigrants in Guangzhou after 2008 was passed through social networks from the destination countries to their country of departure; the negative information conveyed by social networks reduced illegal immigration.

The community-level social capital at arrival was measured by the number of noncompatriot Africans and compatriots living in one's same community. The models showed that the effects of immigrants' social capital in Guangzhou strengthened since 2008. This means that faced with a harsh environment, African immigrants changed their logic of the construction of social capital, which increased the effects of community-level social capital on their migration behavior. ${ }^{\mathrm{k}}$

\section{Conclusions}

This study shows that though China is a nonimmigration and developing country, the current immigration of Africans in Guangzhou has entered its early stage. A migration network connecting Africa and China is rapidly emerging, the process of which can be relatively well analyzed by cumulative causation theory. This study validates the phenomena predicted by cumulative causation theory, such as the effects of social networks and social capital of migrants on their immigration behaviors, the ineffectiveness of individual-level human capital on their immigration possibilities, and the gradually declining social class of immigrants along with the expansion of migration social networks. In addition, it enriches this theory by further analyzing the ineffectiveness of individual social capital on illegal immigration behaviors, as well as by showing the increasing effect of community-level social capital on personal immigration 
decisions, the changing logic in the construction of community-level social capital, and the ways of effectively maintaining it during the migration process. Consistent with the predictions of cumulative causation theory, immigrants' transnational migration social networks as the core of their social capital enhance the self-reinforcement and selfevolution of subsequent migration behaviors. Meanwhile, the changing construction logic of social networks could be made subject to the changing external environment. Thus, social networks are not only maintained but also become increasingly effective.

International trade, global division of labor, flows of labor and capital, and crossborder trade are intertwined, leading to cross-border flows of migration worldwide. As long as the Chinese economy continues to develop and maintains social stability, transnational migration will continue to increase in China. At some point, foreign immigrants will form a powerful pressure group. China has entered the stage in which labor costs are starting to rise; meanwhile, an aging society is also beginning to take shape. Throughout the world, the rise in labor costs and aging are relieved through immigration. Introducing a young foreign labor force that is cheaper than local Chinese workers may be a future solution. Along with the increasing number of international immigrants, the issue of illegal immigrants has started to emerge as well. Take the USA as an example: as the world's most developed country, it is also the country with the most serious problems of illegal immigration. China has proposed building a moderately prosperous society after the first 20 years of this century and reaching the level of moderately developed countries by the mid-twenty-first century. With the rise of domestic economic levels and social living standards, immigration issues will gradually develop from a peripheral social problem into an important social problem that will ultimately affect politics, economy, society, diplomacy, national security, and other issues. It is therefore an urgent matter for Chinese scholars to begin relevant research in the field of international migration as soon as possible.

Based on our above findings, we propose the following policy suggestions: provide more convenient institutional and legal ways of obtaining residence status for those African immigrants who bring in capital and trade opportunities, create a more stringent environment of enforcement for Africans who compete with low-level Chinese physical laborers, and raise African immigrants' entry threshold into China in order to decrease the speed and scale of the decline of social classes of future immigrants to China.

\section{Endnotes}

${ }^{a}$ This is the key point of this study. According to this operational definition, we can prospectively study the pattern of immigrants from Africa to China. However, after a closer scrutiny of this definition, some flaws emerge. These are mainly (1) excluding immigrants with willingness and legal right of residence and (2) including immigrants who want to leave China but cannot for reasons such as economic failure and inability to afford the expenses of leaving. Given the fact that China is a nonimmigrant country and there has been no official definition of an immigrant, this operational definition is the best possible and is close to the current common-sense concept of immigrants in past studies.

${ }^{\mathrm{b}}$ During the survey there were a total of ten investigators who spoke French and nine investigators who spoke English. In our formal survey, there were two qualified 
respondents who spoke Arabic but because we did not have an Arabic translator available, it was impossible for us to complete the interview.

${ }^{c}$ Illegal immigrants are a status-sensitive group. During the investigation in order not to affect the reliability and representativeness of the sample, the relevant regulatory authorities agreed to maintain the original mode of enforcement and even reduced the number of routine inspections at the sites of the surveys and their surrounding areas so that illegal immigrants could safely complete the survey. The government also agreed that all data collected could only be used for academic research purposes. All participants were informed that the use of their personal data was only for academic research purposes at a statistical level. They were promised that their information would be kept secure and anonymous. Also, the investigators discussed respondents' concerns carefully. The qualified respondents were involved in our survey on the condition that they understood the conditions and had given verbal consent before their participation.

${ }^{\mathrm{d}}$ We analyzed the proportions of illegal African immigrants by different places of origin. Nearly $70 \%$ came from Western Africa.

'Today international illegal immigrants often choose a low-risk legal method rather than an illegal way when they enter a country. After their entry they do not leave. When they exceed the duration of residence, they choose to continue their illegal residence. For the operational definition, in order to be consistent with the identification of malicious illegal residence by public security departments, we view illegal residents as foreigners who do not leave after a 12-month extension of their last legitimate visas. We identify a respondent as a legal resident as long as he/she does not meet the definition above. It should be noted that the above operational definition does not result in cumulative reports of illegal residents within 12 months. Figure 2 still displays the number of illegal residents who chose illegal residence as soon as they crossed the Chinese border

${ }^{\mathrm{f}}$ This is an unusual form of the hazard function that differs from the risk functions summarized by Keifer (1988).

${ }^{\mathrm{g}}$ In Chiswick (2008) theory, human capital has no effect prior to one's arrival of destination. Once arriving at the destination, one's human capital takes effect immediately. We are critical of his theory. In our study, we adopted the mastering of the Chinese language as the measurement of human capital at the destination. Remarkably, mastering Chinese can help potential migrants make their decision regarding migration. Different from Chiswick's theory, other scholars operationalized the concept as whether one had visited his or her target country before and whether one had worked in his or her target country before (Massey 1999). These factors apparently affect one's migration decisions when one is still in the country of departure, rather than effective only after one's arrival at the destination. Since all of the objects of our study were in Guangdong, this research does not violate the theoretical assumption of Chiswick's theory.

${ }^{\mathrm{h}}$ The legal consequences include fines, repatriation, and even imprisonment; one will also be registered on a blacklist and will not be able to obtain a visa to China for a number of years. Being on a blacklist also means the fracture of Africans' social networks and business in China. This often results in a total loss of many years of hard work. 
${ }^{\mathrm{i}}$ Here we label the people who did not recruit any new respondents and only completed their own questionnaire as one group. There must be some reason why they did not recruit any new respondents, such as their limited social network or lack of trust in Chinese society.

${ }^{j}$ The data obtained by the RDS method used by current academia are mainly for the demographic description of hidden and sparse groups rather than for causal analysis. For example, Frost et al. (2006) obtained interactive tables from RDS data and studied the causal model. This study analyzes complex multicausal models, which may have some limitations.

${ }^{\mathrm{k}}$ This study devotes a section to the analysis of the post-2008 construction of the social capital of African foreigners in Guangzhou; faced with a more stringent environment of enforcement, they changed the constructive logic of their social interaction networks. They were more likely to adopt the strategies of scattered occupancy and closer contact with people from their motherlands in order to enhance the function of their networks. This part is omitted in this article due to space limitations.

\section{Competing interests}

The authors declare that they have no competing interests.

Received: 25 July 2014 Accepted: 25 July 2014

Published online: 31 October 2014

References

Borjas, George J. 1994. The economics of immigration. Journal of Economic Literature 32(4): 1667-1717.

Chiswick, Barry R. 2008. Are Immigrants Favorably Self-Selected? An Economic Analysis. In Migration Theory: Talking Across Disciplines, Secondth ed, ed. D Caroline Brettell and F James Hollifield. New York: Routledge.

Frost, S, K Brouwer, M Firestone Cruz, R Ramos, ME Ramos, R Lozada, C Magis-Rodriguez, and S Strathdee. 2006. Respondent driven sampling of injection drug users in two U.S.- Mexico border cities: recruitment dynamics and impact on estimates of hiv and syphilis prevalence. Journal of Health 83(Ramos R): 6.

Gelman, Andrew, and Jennifer Hill. 2007. Data Analysis Using Regression and Multilevel/Hierarchical Models. New York: Cambridge University Press.

Goel, Sharad, and Matthew J Salganik. 2009. Respondent-Driven Sampling as Markov chain Monte Carlo. Stat In Medicine 28: 2202-2229.

Greenwood, Michael J. 1971. A regression analysis of migration to urban areas of less-developed countries: The case of India. Journal of Regional Science 11: 253-262.

Grubel, Herbert B, and Anthonoy D Scott. 1966. The international flow of human capital. The American Economic Review 56: 268-274.

Heckathorn, Douglas D. 1997. Respondent-driven sampling: A new approach to the study of hidden populations. Social Problems 44(2): 174-199.

Heckathorn, Douglas D. 2002. "Respondent-driven sampling II: Deriving valid population estimates from chain-referral samples of hidden populations. Social Problems 49: 11-14.

Heckathorn, Douglas D. 2007. Extensions of respondent-driven sampling: Analyzing continuous variables and controlling for differential recruitment. Sociological Methodology 37:151-207

Kallbfleisch, JD, and RL Prentice. 1980. Statistical Analysis of Failure Time Data. New York: Wiley.

Keifer, NM. 1988. Economic Duration Data and Hazard Functions. Journal of Economic Literature 26: 646.

Li, Zhigang, Desheng Xue, Michael Lyons, and Alison Brown. 2008. The African Enclave of Guangzhou: A Case Study of Xiaobeilu (in Chinese). Acta Geographica Sinix 63(2): 207-218.

Li, Zhigang, Xue Desheng, Feng Du, and Ying Zhu. 2009. The local response of transnational social space under globalization in urban China: A case study of Africans living inXiaobei, Guangzhou (in Chinese). Acta Geographica Sinix 28(4): 920-932.

Liang, Zai, Miao David Chunyu, Guotu Zhuang, and Ye Wenzhen. 2008. Cumulative causation, market transition, and emigration from China. American Journal of Sociology 114(3): 706-737.

Massey, Douglas S. 1988. International migration and economic development in comparative perspective. Population and Development Review 14: 383-414.

Massey, Douglas S. 1990a. The Social and Economic Origins of Immigration. Annals of the American Academy of Political and Social Science 510(1): 60-72.

Massey, Douglas S. 1990b. Social Structure, Household Strategies, and the Cumulative Causation of Migration. Population Index 56: 3-26.

Massey, Douglas S. 1995. The new immigration and ethnicity in the United States. Population and Development Review 21(3): 631-652.

Massey, Douglas S. 1999. International Migration at the Dawn of the Twenty-First Century: The Role of the State'. Population and Development Review 25(2): 303-322. 
Massey, Douglas S, Rafael Alarcòn, Jorge Durand, and Humberto González. 1987. Return to Aztlan: The Social Process of International Migration from Western Mexico. Berkeley: University of California Press.

National Bureau of Statistics. 2011. Primary data of registered Hong Kong, Macao and Taiwan residents as well as foreigners in The Sixth National Census in 2010. http://news.xinhuanet.com/politics/2011-04/29/c_121365315.htm. Accessed on April $3^{\text {rd }}, 2012$.

Nelson, Joan. 1976. Sojourners versus new urbanites: Causes and consequences of temporary versus permanent cityward migration in developing countries. Economic Development and Cultural Change 24(4): 721-757.

Petersen, William. 1958. A general typology of migration. American Sociological Review 23(3): 256-266.

Salganik, MJ, and DD Heckathorn. 2004. Sampling and estimation in hidden populations using respondent-driven sampling. Sociological Methodology 34

Schonlau, Matthias, and Elisabeth Liebau. 2012. Respondent-driven sampling. The Stata Journal 12(1): 72-93.

Singer, JD, and JB Willett. 2003. Applied longitudinal data analysis: Modeling change and event occurrence. London: Oxford University Press.

Stalker, Peter. 2001. The no-nonsense guide to international migration. Oxford, UK: New International Publications. Stark, Oded, and David Bloom. 1985. The new economics of labor migration. American Economic Review 75: 173-178.

Stark, Oded, and Edward J Taylor. 1989. Relative deprivation and international migration. Demography 26: 1-14.

Stark, Oded, and Edward J Taylor. 1991. Migration incentives, migration types: The role of relative deprivation. The Economic Journal 101: 1163-1178.

Taylor, Edward J. 1986. Differental migration, networks, information and risk. Human Capital and Development 4: 147-171.

Taylor, Edward J. 1987. Undocumented Mexico-U.S. migration and the returns to households in rural Mexico. American Journal of Agricultural Economics 69(3): 626-638.

Wallerstein, Immanuel. 2006. World system in transition: Wallerstein commentaries. Beijing: Social Sciences Academic Press. Translated by Aiguo Lu.

Winship, Christopher, and Larry Radbill. 1994. Sampling weights and regression analysis. Sociological Methods and Research 23(2): 230-257.

Xiao, Jing. 2006. Three Categories of the US's immigration. 21st Century 9: 50-51.

Xu, Tao. 2009b. Weakening, Rupture and Reconstruction of Social Supports of Africans in Guangzhou (in Chinese). South Population 24(4): $34-44$

Zhao, Yandong, and J Peterson. 2007. Respondent Driven Sampling: Method and Practice for the Research on Hidden Population (in Chinese). The Chinese Journal of Sociology 2(27): 192-205.

doi:10.1186/s40711-014-0002-6

Cite this article as: Liang: The causal mechanism of migration behaviors of African immigrants in Guangzhou: from the perspective of cumulative causation theory. The Journal of Chinese Sociology 2014 1:2.

\section{Submit your manuscript to a SpringerOpen ${ }^{\circ}$ journal and benefit from:}

- Convenient online submission

- Rigorous peer review

- Immediate publication on acceptance

- Open access: articles freely available online

- High visibility within the field

- Retaining the copyright to your article

Submit your next manuscript at $\boldsymbol{\nabla}$ springeropen.com 